\title{
Preparation and Characterization of Nickel-
}

\section{and Cobalt-doped Magnetites}

\author{
Maria de Fátima Fontes Lelis ${ }^{\mathrm{a}}{ }^{*}$, José Domingos Fabris ${ }^{\mathrm{a}}$, Wagner da Nova Mussel ${ }^{\mathrm{a}}$, \\ Armando Yoshihaki Takeuchi ${ }^{\mathrm{b}}$ \\ a Departamento de Química, ICEx, Universidade Federal de Minas Gerais \\ Campus - Pampulha, 31270-901 Belo Horizonte - MG, Brazil \\ ${ }^{\mathrm{b}}$ Centro Brasileiro de Pesquisas Físicas, \\ Rua Dr. Xavier Sigaud, 150, 22290-180 Rio de Janeiro - RJ, Brazil
}

Received: November 11, 2001; Revised: March 3, 2003

\begin{abstract}
Nickel- and cobalt-doped magnetites were prepared by a co-precipitation method and studied in some detail, in an effort to identify some effects of the doping cations on the magnetic, crystallographic and morphological properties of the resulting spinel. The synthetic samples were characterized by conventional chemical analysis, powder X-ray diffractometry, Mössbauer spectroscopy, saturation magnetization and scanning electron microscopy. From chemical analysis, the continuous increase of $\mathrm{Ni}^{2+}$ or $\mathrm{Co}^{2+}$ is accompanied by a simultaneous decrease of the $\mathrm{Fe}^{2+}$ contents, in the spinel structure. The magnetization values also decrease continuously with increasing doping cation contents. Mössbauer parameters are characteristic of substituted magnetites and indicate the presence of a single phase only. Based on the inverted intensities of the lines 1 (leftmost, on the negative Doppler velocity scale) and 2 of Mössbauer spectra of doped samples, relatively to the pure magnetite, it was assumed that the isomorphical substitution occurs preferentially on octahedral coordination sites of the spinel structure. The coercive field of these ferrites decrease steadily with $\mathrm{Ni}^{2+}$ but increases with $\mathrm{Co}^{2+}$ contents, reaching a maximum at $x=0.38$, in the general formula $\mathrm{Co}_{x} \mathrm{Fe}_{3-x} \mathrm{O}_{4}$.
\end{abstract}

Keywords: Mössbauer, ferrite, magnetization

\section{Introduction}

Magnetic ferrites are used in many technological applications as those of permanent magnets, microwave absorbers, catalysts and chemical sensors ${ }^{1-3}$. Magnetite and cationsubstituted magnetites are some of the most extensively studied spinels. Despite of that, certain aspects of their electronic and magnetic properties are still not fully understood. The electrical conductivity mechanism of spinel ferrites containing $\mathrm{Fe}^{2+}$ ions is explained by the electron hopping effect between $\mathrm{Fe}^{2+}$ and $\mathrm{Fe}^{3+}$ ions in octahedral sites ${ }^{4,5}$. The cation distribution between tetrahedral (A) and octahedral (B) sites is a fundamental aspect on the understanding of their magnetic properties. Nickel-doped magnetite, $\mathrm{Ni}_{x} \mathrm{Fe}_{3-x} \mathrm{O}_{4}$, is an inverse spinel in which the $\mathrm{Co}^{2+}$ are assumed to occupy preferentially $\mathrm{B}$ sites whereas $\mathrm{Fe}^{3+}$ are somehow distributed between A and B sites. The degree of inversion (meaning the proportion of divalent cations occupying octahedral sites) of the doped-magnetite may vary, depending on the synthesis conditions ${ }^{6,7}$.

The replacement of $\mathrm{Fe}^{2+}$ by $\mathrm{Co}^{2+}$ or $\mathrm{Ni}^{2+}$ does not change essentially the nature of crystallographic structure but its unit cell dimension. The cation distribution in spinels has long been a topic of interest as it affects their magnetic, electric and thermodynamic propertiesb ${ }^{8-10}$. In addition, it has been found that ferrite particles of similar composition differ on their magnetic properties depending on the preparation method. One reason for such a behavior is believed to be differences in particle size. Decreasing the particle sizes leads to an increase of non-magnetic species on the particle surface ${ }^{6}$. Various preparation procedures, including hydrothermal, co-precipition, sol-gel methods and mechanical alloying have been reportedly used to produce ferrites ${ }^{11}$. Following the chemical via, some coarse particles may be formed due to agglomeration during the dehydration step.

*e-mail: mfflelis@cce.ufes.br

Trabalho apresentado no I Simpósio Mineiro de Ciências dos Materiais, Ouro Preto, Novembro de 2001. 
In the present paper we report the preparation of nickeland cobalt-doped magnetites by a co-precipitation method and some analysis of their cation distribution, by means of X-ray diffractometry (XRD), Mössbauer spectroscopy, saturation magnetization and scanning electron microscopy (SEM).

\section{Experimental methods}

$\mathrm{Co}_{\mathrm{x}} \mathrm{Fe}_{3-\mathrm{x}} \mathrm{O}_{4}(0 \leq \mathrm{x} \leq 0.75)$ and $\mathrm{Ni}_{x} \mathrm{Fe}_{3-\mathrm{x}} \mathrm{O}_{4}(0 \leq \mathrm{x} \leq 0.54)$ were prepared by co-precipitation. The syntheses were carried out by precipitation in aqueous solutions of $\mathrm{Co}^{2+}, \mathrm{Ni}^{2+}$ and $\mathrm{Fe}^{3+}$ chlorides $\left(\mathrm{FeCl}_{3} \cdot 6 \mathrm{H}_{2} \mathrm{O}, \mathrm{CoCl}_{2} \cdot 6 \mathrm{H}_{2} \mathrm{O}\right.$ or $\mathrm{NiCl}_{2} \cdot 6 \mathrm{H}_{2} \mathrm{O}$ ), at room temperature, by adding ammonium hydroxide. The precipitate was washed out with ammonium acetate, dried and decomposed in a $\mathrm{N}_{2}$ atmosphere at $420{ }^{\circ} \mathrm{C}$ for $2 \mathrm{~h}^{12}$. The prepared materials were first characterized by chemical analysis. Nickel, cobalt and iron were determined by dissolving samples with hydrochloric acid 1:1. Nickel and cobalt were analyzed by atomic absorption (Carls Zeiss Jena AAS). Higher contents of iron were determined by volumetric method titration with $\mathrm{K}_{2} \mathrm{Cr}_{2} \mathrm{O}_{7}{ }^{13}$. $\mathrm{Fe}^{2+}$ was determined by dissolving samples in concentrated $\mathrm{HCl}$ un- der a $\mathrm{CO}_{2}$ atmosphere, followed by the volumetric determination with $\mathrm{K}_{2} \mathrm{Cr}_{2} \mathrm{O}_{7}$. The morphology of the produced grains was determined by scanning electron microscopy (Jeol JSM-840 A). The X-ray diffraction patterns were obtained with a Rigaku Geigerflex diffractometer using CuKa radiation. Results confirm the existence of the spinel phase only. $\mathrm{NaCl}$ was used as internal standard. The Mössbauer spectra were obtained with a conventional constant acceleration transmission setup and a $\mathrm{Co}^{57} / \mathrm{Rh}$ source. The isomer shifts are quoted relatively to $\alpha-\mathrm{Fe}$. The saturation magnetization measurements were performed with a portable magnetometer ${ }^{14}$. Magnetization curves as a function of the applied magnetic field were performed in a conventional vibrating sample magnetometer, at room temperature.

\section{Results and discussion}

The proposed chemical formulae and measured magnetization of all samples are listed in Table 1 . The combination of these chemical results and Mössbauer parameters suggests that the amounts of $\mathrm{Fe}^{3+}$ in samples remain nearly unaffected and those of $\mathrm{Fe}^{2+}$ continually decrease with increasing amounts of cobalt or nickel. Fitted Mössbauer pa-

Table 1. Chemical formula, saturation magnetization and room-temperature Mössbauer parameters of samples. $\delta=$ isomer shift relative to $\alpha-\mathrm{Fe} ; 2 \varepsilon_{\mathrm{Q}}=$ quadrupole shift; $\mathrm{B}_{\mathrm{hf}}=$ hyperfine field; $\mathrm{RA}=$ relative spectral area, and $\left[\mathrm{Fe}^{3+}\right]$ and $\left\{\mathrm{Fe}^{3+2+}\right\}=$ tetrahedral and octahedral sites respectively.

\begin{tabular}{|c|c|c|c|c|c|c|c|}
\hline Spinel formula & $\mathrm{s} / \mathrm{J} \mathrm{T}^{-1} \mathrm{~kg}^{-1}$ & Site & $\mathrm{d} / \mathrm{mm} \mathrm{s}^{-1}$ & $2 \varepsilon_{\mathrm{Q}} / \mathrm{mm} \mathrm{s}^{-1}$ & $\mathrm{~B}_{\mathrm{hf}} / \mathrm{T}$ & $\mathrm{RA} / \%$ & $\frac{\left\{\mathrm{Fe}^{3+/ 2+}\right\}}{\left[\mathrm{Fe}^{3+}\right]}$ \\
\hline \multirow{2}{*}{$\mathrm{Fe}_{3} \mathrm{O}_{4}$} & 92.5 & {$\left[\mathrm{Fe}^{3+}\right]$} & 0.28 & 0.00 & 49.2 & 36 & 1.89 \\
\hline & & $\left\{\mathrm{Fe}^{3+/ 2+}\right\}$ & 0.66 & 0.01 & 46.2 & 64 & \\
\hline \multirow{2}{*}{$\mathrm{Fe}_{2.93} \mathrm{Co}_{0.07} \mathrm{O}_{4}$} & 80.9 & {$\left[\mathrm{Fe}^{3+}\right]$} & 0.25 & -0.03 & 49.4 & 43 & 1.41 \\
\hline & & $\left\{\mathrm{Fe}^{3+/ 2+}\right\}$ & 0.69 & 0.02 & 46.5 & 57 & \\
\hline \multirow{2}{*}{$\mathrm{Fe}_{2.81} \mathrm{Co}_{0.19} \mathrm{O}_{4}$} & 66.6 & {$\left[\mathrm{Fe}^{3+}\right]$} & 0.24 & -0.04 & 49.3 & 45 & 1.28 \\
\hline & & $\left\{\mathrm{Fe}^{3+/ 2+}\right\}$ & 0.68 & 0.01 & 47.1 & 54 & \\
\hline \multirow{2}{*}{$\mathrm{Fe}_{2.62} \mathrm{Co}_{0.38} \mathrm{O}_{4}$} & 50.0 & {$\left[\mathrm{Fe}^{3+}\right]$} & 0.26 & -0.03 & 49.3 & 50 & 1.06 \\
\hline & & $\left\{\mathrm{Fe}^{3+/ 2+}\right\}$ & 0.70 & 0.02 & 47.2 & 50 & \\
\hline \multirow{2}{*}{$\mathrm{Fe}_{2.37} \mathrm{Co}_{0.63} \mathrm{O}_{4}$} & 46.3 & {$\left[\mathrm{Fe}^{3+}\right]$} & 0.26 & -0.03 & 49.3 & 55 & 0.87 \\
\hline & & $\left\{\mathrm{Fe}^{3+/ 2+}\right\}$ & 0.68 & 0.02 & 47.4 & 45 & \\
\hline \multirow{2}{*}{$\mathrm{Fe}_{2.25} \mathrm{Co}_{0.75} \mathrm{O}_{4}$} & 39.9 & {$\left[\mathrm{Fe}^{3+}\right]$} & 0.27 & -0.02 & 49.1 & 53 & 0.94 \\
\hline & & $\left\{\mathrm{Fe}^{3+/ 2+}\right\}$ & 0.69 & 0.03 & 47.4 & 47 & \\
\hline \multirow{2}{*}{$\mathrm{Fe}_{2.96} \mathrm{Ni}_{0.04} \mathrm{O}_{4}$} & 80.6 & {$\left[\mathrm{Fe}^{3+}\right]$} & 0.26 & -0.03 & 49.1 & 44 & 1.35 \\
\hline & & $\left\{\mathrm{Fe}^{3+/ 2+}\right\}$ & 0.70 & 0.02 & 46.4 & 56 & \\
\hline \multirow[t]{2}{*}{$\mathrm{Fe}_{2.90} \mathrm{Ni}_{0.10} \mathrm{O}_{4}$} & 76.6 & {$\left[\mathrm{Fe}^{3+}\right]$} & 0.26 & -0.03 & 49.2 & 47 & 1.20 \\
\hline & & $\left\{\mathrm{Fe}^{3+/ 2+}\right\}$ & 0.69 & 0.01 & 46.5 & 53 & \\
\hline \multirow{2}{*}{$\mathrm{Fe}_{2.86} \mathrm{Ni}_{0.14} \mathrm{O}_{4}$} & 73.4 & {$\left[\mathrm{Fe}^{3+}\right]$} & 0.26 & -0.03 & 49.4 & 49 & 0.92 \\
\hline & & $\left\{\mathrm{Fe}^{3+/ 2+}\right\}$ & 0.70 & 0.01 & 46.8 & 51 & \\
\hline \multirow{2}{*}{$\mathrm{Fe}_{2.72} \mathrm{Ni}_{0.28} \mathrm{O}_{4}$} & 70.1 & {$\left[\mathrm{Fe}^{3+}\right]$} & 0.28 & -0.02 & 49.3 & 52 & 0.98 \\
\hline & & $\left\{\mathrm{Fe}^{3+/ 2+}\right\}$ & 0.70 & 0.01 & 47.1 & 48 & \\
\hline \multirow{2}{*}{$\mathrm{Fe}_{2.46} \mathrm{Ni}_{0.54} \mathrm{O}_{4}$} & 66.3 & {$\left[\mathrm{Fe}^{3+}\right]$} & 0.28 & -0.02 & 49.3 & 53 & 0.94 \\
\hline & & $\left\{\mathrm{Fe}^{3+/ 2+}\right\}$ & 0.69 & 0.02 & 47.2 & 47 & \\
\hline
\end{tabular}


rameters indicate a progressive decreasing of the relative subspectral areas corresponding to the octahedral iron of the spinel structure. The decrease in magnetization in dopedsamples also suggests that cobalt or nickel is actually replacing iron in the lattice as $\mathrm{Fe}^{2+}$ in octahedral coordination has higher magnetic moment than $\mathrm{Ni}^{2+15}$.

Typical morphologies of the $\mathrm{Fe}_{3} \mathrm{O}_{4}, \mathrm{Co}_{0.75} \mathrm{Fe}_{2.25} \mathrm{O}_{4}$ and $\mathrm{Ni}_{0.54} \mathrm{Fe}_{2.46} \mathrm{O}_{4}$ particles, as they were visualized by $\mathrm{SEM}$, are shown in Fig. 1. It is verified that the more magnetite is doped with nickel the more it tends to form uniform ag-
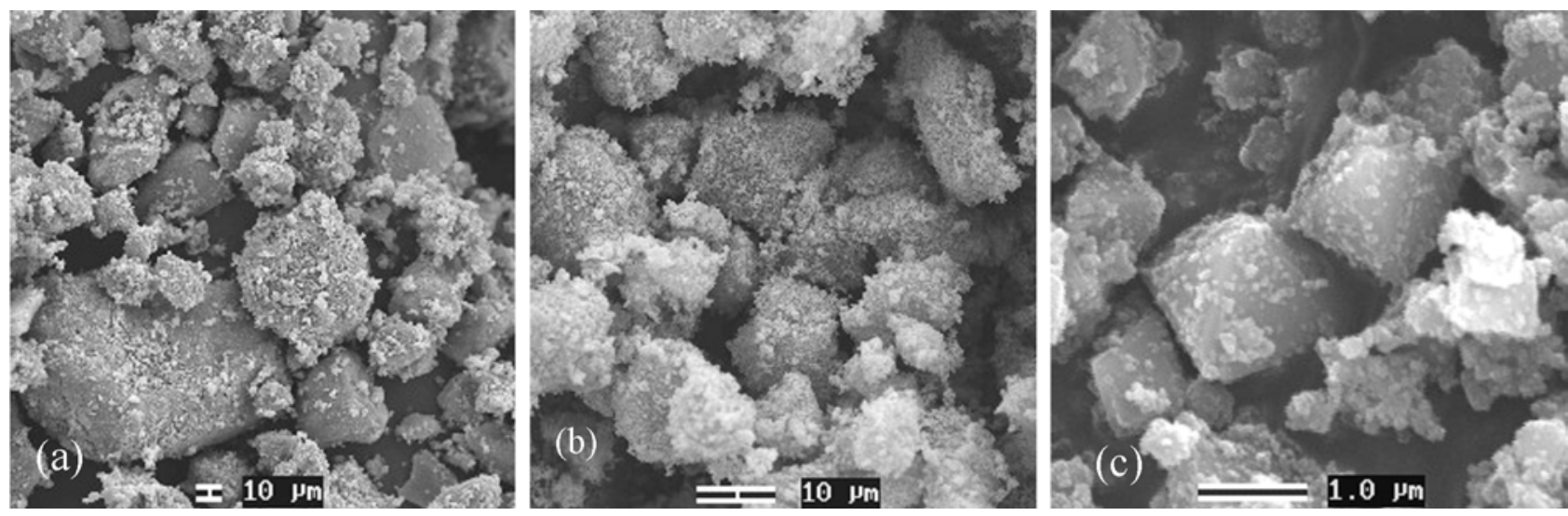

Figure 1. Scanning electron micrograph of the (a) $\mathrm{Fe}_{3} \mathrm{O}_{4}$; (b) $\mathrm{Fe}_{2.46} \mathrm{Ni}_{0.54} \mathrm{O}_{4}$; (c) $\mathrm{Fe}_{2.25} \mathrm{Co}_{0.75} \mathrm{O}_{4}$.

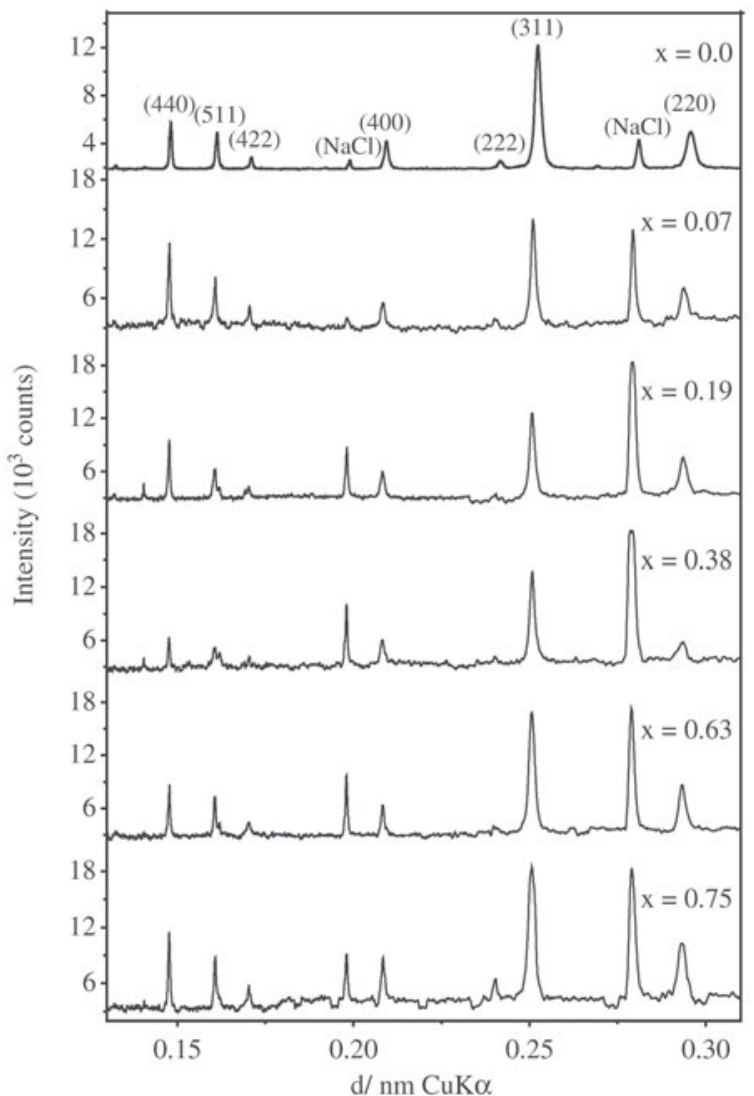

(a)

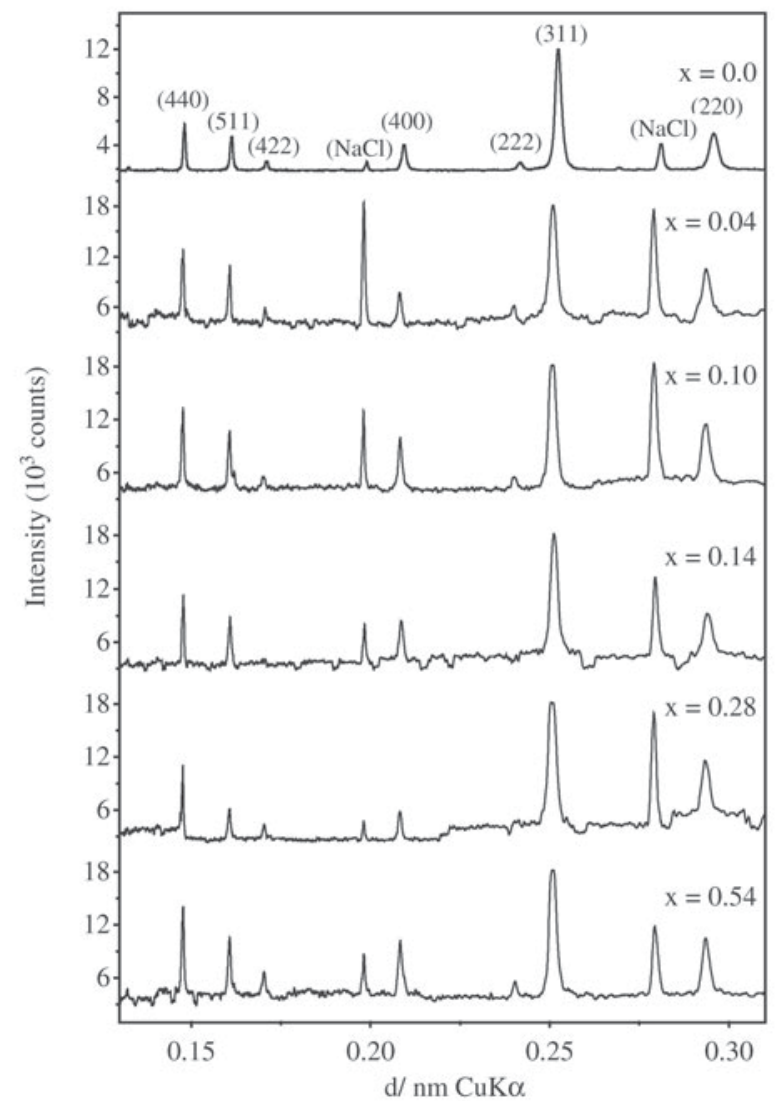

(b)

Figure 2. Powder X-ray patterns for the (a) $\mathrm{Fe}_{3-x} \mathrm{Co}_{x} \mathrm{O}_{4}(0 \leq x \leq 0.75)$; (b) $\mathrm{Fe}_{3-x} \mathrm{Ni}_{x} \mathrm{O}_{4}(0 \leq x \leq 0.54)$ samples. $\mathrm{NaCl}$ is the internal standard. 


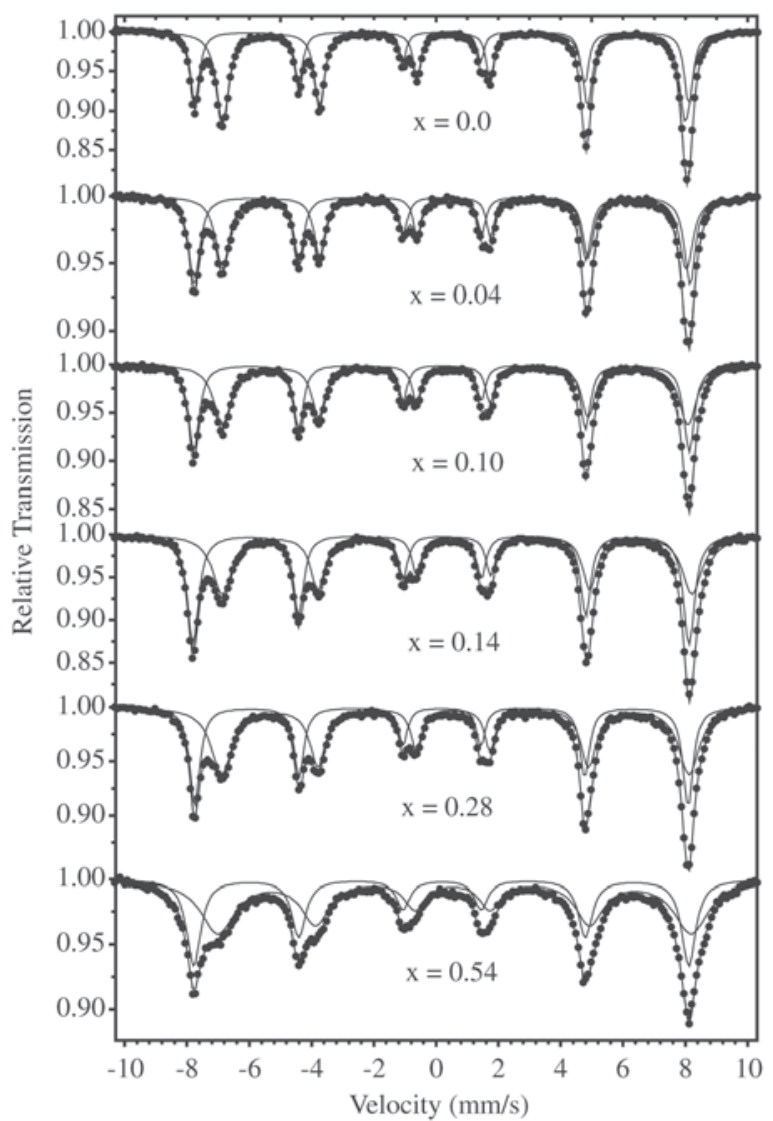

(a)

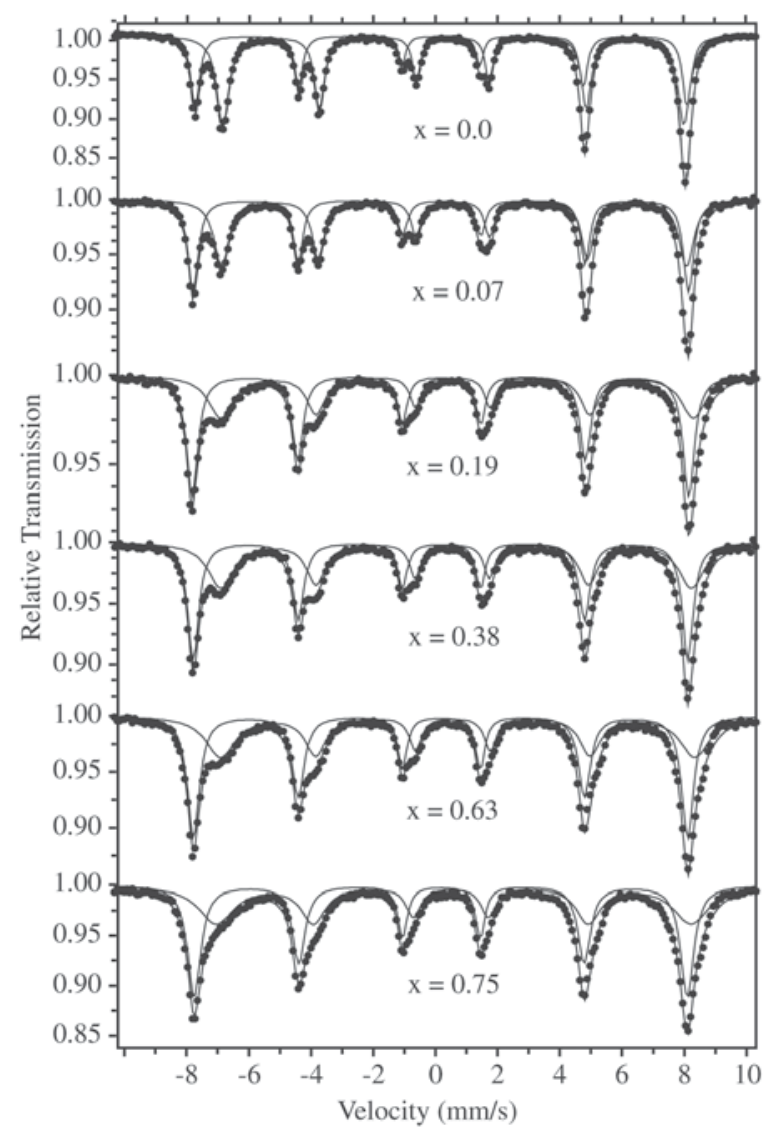

(b)

Figure 3. Room-temperature Mössbauer spectra for the (a) $\mathrm{Fe}_{3-x} \mathrm{Co}_{x} \mathrm{O}_{4}(0 \leq x \leq 0.75)$; (b) $\mathrm{Fe}_{3-x} \mathrm{Ni}_{x} \mathrm{O}_{4}(0 \leq x \leq 0.54)$ samples.

glomerates of very small particles. Differently, Co-doped magnetites grow particles of octahedral habit.

XRD patterns show that all samples are well crystallized (Fig. 2) with a cubic structure ${ }^{16}$, there is no appreciable line broadening or detectable sign of any other crystalline or amorphous phase.

The room temperature Mössbauer spectra show a typical hyperfine pattern consisting of two overlapping six-line magnetic splitting structure, in all samples (Fig. 3), assignable to ${ }^{57} \mathrm{Fe}$ in octahedral and in tetrahedral sites of the spinel lattice. The recoilless fraction of the octahedral iron $\left(f_{\left\{\mathrm{Fe}^{3+2+2}\right\}}\right)$ is assumed to be $6 \%$ lower than that of the tetrahedral site $\left(f_{\left[\mathrm{Fe}^{3+}\right]}\right)$, at room temperature ${ }^{6}$. The relative occupancy of iron ions in octahedral $\left\{\mathrm{Fe}^{3+/ 2+}\right\}$ and tetrahedral $\left[\mathrm{Fe}^{3+}\right]$ coordination sites can be then estimated from the relative subspectral areas (RA; Table 1) of the corresponding Mössbauer spectrum:

$$
\frac{\left\{\mathrm{Fe}^{3+12+}\right\}}{\left[\mathrm{Fe}^{3+}\right]}=\frac{\mathrm{RA}_{\left\{\mathrm{Fe}^{3+2+2+}\right\}}}{0.94 \times \mathrm{RA}_{\left[\mathrm{Fe}^{3+}\right]}}
$$

The so deduced values are presented in Table 1 . The $\frac{\left\{\mathrm{Fe}^{3+/ 2+}\right\}}{\left[\mathrm{Fe}^{3+}\right]}$ ratio decreases with increasing cobalt or nickel contents. Also, the hyperfine magnetic field of the tetrahedral site remains essentially unaltered whereas that of the octahedral iron increases with increasing cobalt contents in the spinel structure. This may indicate that the foreign ions tend to replace referentially iron in octahedral coordination.

The saturation magnetization and the coercive field at room temperature depend on the concentration of $\mathrm{Ni}^{2+}$ or $\mathrm{Co}^{2+}$. The hysteresis loop of the pure magnetite is compared with those of the doped-samplles in Fig. 4. It can be observed that the coercive field decreases steadily with $\mathrm{Ni}^{2+}$ content but increases with $\mathrm{Co}^{2+}$, reaching a maximum at $x=0.38$, in the general formula, $\mathrm{Co}_{\mathrm{x}} \mathrm{Fe}_{3-x} \mathrm{O}_{4}$. One can also see that the saturation magnetization limit is higher and that the coercive field strongly depends on the cobalt proportion. It is well known that the saturation magnetization of a spinel ferrite largely depends on its composition and particle size, while the coercive field depends on composition, 


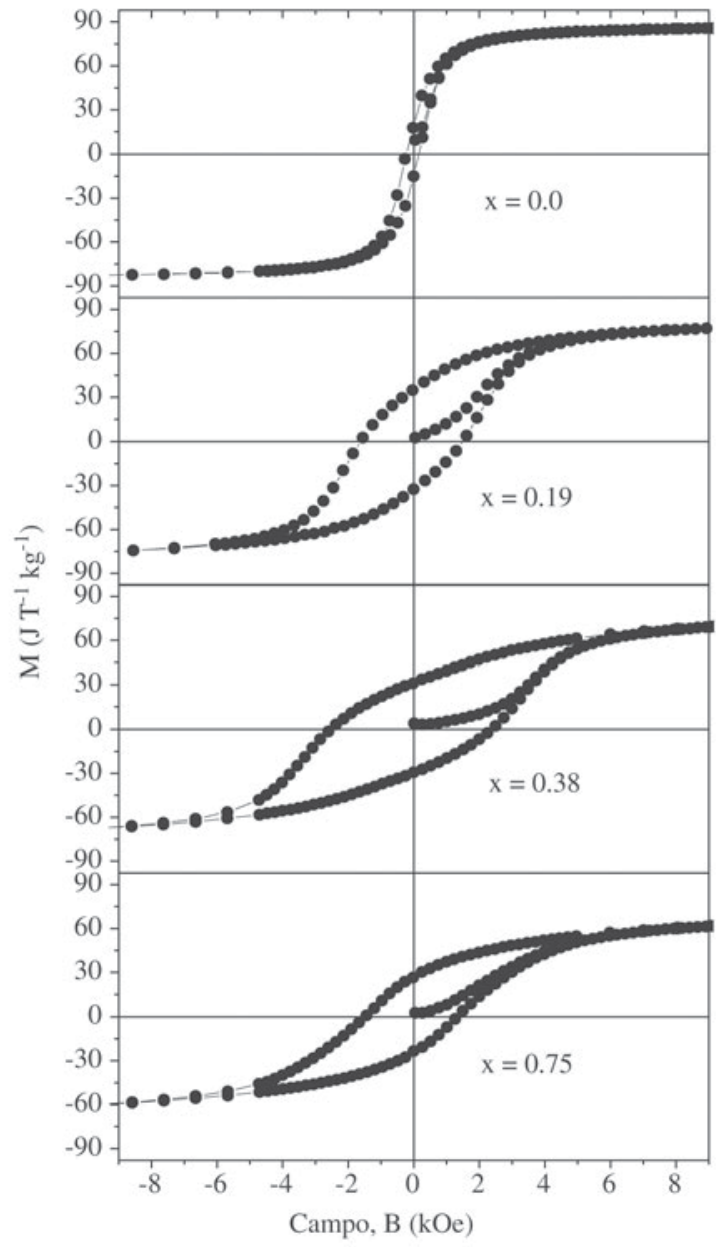

(a)

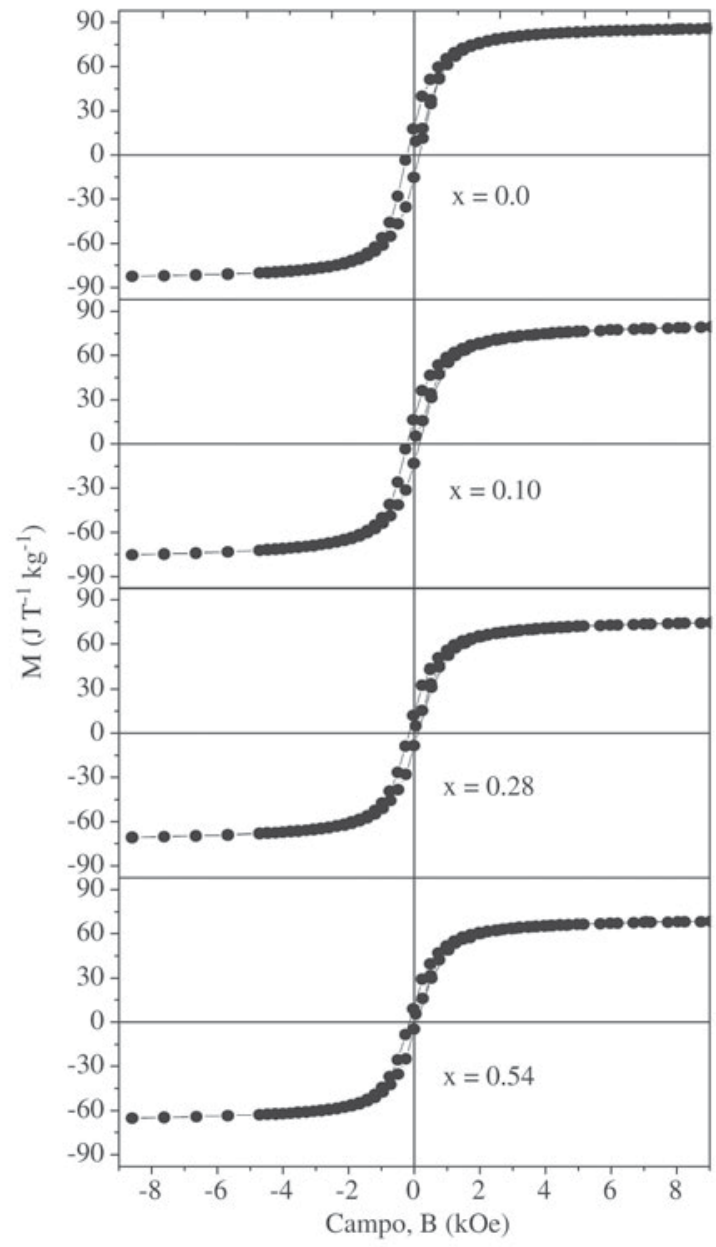

(b)

Figure 4. Hysteresis loops recorded at room temperature for the (a) $\mathrm{Fe}_{3-x} \mathrm{Co}_{x} \mathrm{O}_{4}(0 \leq x \leq 0.75)$; (b) $\mathrm{Fe}_{3-x} \mathrm{Ni}_{x} \mathrm{O}_{4}(0 \leq x \leq 0.54)$ samples.

particle size and shape. Likewise, the coercive field of these ferrites decreases with the degree of $\mathrm{Ni}^{2+}$ substitution. This can be interpreted as being due to the fact that the magnetocrystalline anisotropy constant of $\mathrm{Fe}_{3} \mathrm{O}_{4}$ is higher than that of $\mathrm{NiFe}_{2} \mathrm{O}_{4}$.

\section{Conclusions}

The present study showed that for $\mathrm{Co}_{\mathrm{x}} \mathrm{Fe}_{3-\mathrm{x}} \mathrm{O}_{4}$ $(0 \leq x \leq 0.75)$ and $\mathrm{Ni}_{x} \mathrm{Fe}_{3-\mathrm{x}} \mathrm{O}_{4}(0 \leq \mathrm{x} \leq 0.54)$ samples obtained by a co-precipitation synthesis, room temperature Mössbauer spectra evidence an increase of the hyperfine magnetic field due to ${ }^{57} \mathrm{Fe}$ in octahedral coordination sites, according to the doping degree of the resulting spinel. In both cases, $\mathrm{Ni}^{2+}$ and $\mathrm{Co}^{2+}$, doping-cations tend to replace iron preferentially in octahedral coordination sites. The more the magnetite is doped with nickel the more it tends to form uniform agglomerates of very small particles, whilst Codoped magnetites tend to grow particles of octahedral habit. The room temperature magnetic hysteresis loops of these doped-magnetites depend on their composition and particle size. The coercive field decreases with $\mathrm{Ni}^{2+}$ and increases with the $\mathrm{Co}^{2+}$ substitution.

\section{Acknowledgements}

This work was financially supported by FAPEMIG, CAPES, CNPq and FINEP (Brazil).

\section{References}

1. Adam, J.D., Krishnaswamy, S.V., Talisa S. H. \& Yoo, K.C., J. Magn. Mag. Mater, v. 83, p. 419-424, 1990.

2. Lee, J.G., Park, J.Y.; Oh, Y-J \& Kim, C.S., Journal of Applied Physics, v. 84, n. 5, p. 2801-2804, 1998. 
3. Petrosius, S.C.; Drago, R.S.; Young, V. \& Grunewald, G.C. J. Am. Chem. Soc., v. 115, p. 6131-6137, 1993.

4. Verwey, E.J.W.; Haayman, P.W. Physica 8 , p. 979-987, 1941.

5. Ferguson Jr, G.A.; Haas, M. Physical Review, v. 112 , p. 1130-1139, 1958.

6. Sawatzky, G.A; Van Der Woude, F.; Morrish, A.H. Physical Review. 187:747-757, 1969.

7. Haneda, K.; Morrish, A. H. J.Appl. Phys, v. 63, n. 8, p. 765-771, 1988.

8. Goss, C.J. Phys Chem Minerals, v. 16, p. 164-171, 1988.

9. Lenglet, M.; Lefez, B. Solid State Communications, v. 98, n. 8, p. 689-694, 1996.

10. Mendelovici, E., Villalba, R.; Sagarzazu, A.
Thermochimica Acta, v. 318, p. 51-56, 1998.

11. Deshpande, C.E.; Date, S.K. Indian Journal of Chemistry, v. 35A, p. 353-365, 1996.

12. De Abreu Filho, P.P.; Pinheiro, E.A. ; Galembeck, F.; Labaki, L.C. Reactivity of solids, v. 3, p. 241-250, 1987.

13. Jeffery, P.G.; Hutchison, D. Chemical Methods of Rock Analysis, 3.ed. Oxford, Pergamon Press, p. 379, 1981.

14. Coey, J.M.D.; Cugat, O.; Mac Cauley, J.; Fabris, J.D. Revista de Física Aplicada e Instrumentação. São Paulo, v. 7, p 25-30, 1992.

15. Huang, C.; Matijevic, E. Solid State Ionics, v. 84, p. 249-258, 1996.

16. Fleet, M.E. Acta Crystallographica Section B, v.37, p. 917-920, 1981. 